\title{
CFD simulation of turbulent flow of drill cuttings and parametric studies in a horizontal annulus
}

\author{
Mastaneh Hajipour ${ }^{1}$ (D)
}

Received: 7 November 2019 / Accepted: 28 May 2020 / Published online: 31 May 2020

(c) Springer Nature Switzerland AG 2020

\begin{abstract}
Understanding the mechanisms of cuttings transport and investigating the effects of different parameters is necessary to design an efficient cuttings transport process. Improper hole cleaning leads to the accumulation of drill cuttings in the well annulus and causes many problems such as rotational speed reduction, stuck pipe, circulation loss, and drill bit abrasion especially in horizontal drilling. In this study, computational fluid dynamics (CFD) were used for simulation of turbulent two phase flow in a horizontal annulus including a Herschel-Bulkley drilling fluid. The Lagrangian-Eulerian/ discrete element method approach was adopted for description of the particle flow, interparticle and particle-wall interactions. Simulation results were compared and validated against published experimental data in the literature and j simulation results indicate that at constant drilling rate, the major factors that affects hole cleaning in horizontal wellbores are drill pipe rotational speed, drilling fluid rheology and velocity. Results of this study show the reliability of CFD analysis to simulate cuttings transport process which can minimize the difficult experimental measurements.
\end{abstract}

Keywords CFD simulation · Turbulent flow · Cuttings transport · Horizontal well

\section{List of symbols}

\section{Latin letters}

$A_{w b} \quad$ Wellbore cross sectional area

$\mathrm{d}_{\mathrm{p}} \quad$ Solid particles diameter

FC Contact force

$F_{D} \quad$ Drag force

$F_{M} \quad$ Magnus force

$F_{P} \quad$ Pressure gradient force

$F_{S} \quad$ Shear lift force

g Gravitational acceleration

GPM Fluid flow rate

$I_{p} \quad$ Particle moment of inertia

$K \quad$ Consistency factor

$\dot{m}_{p} \quad$ Particle mass flow rate

n Power law index

P Pressure

$R_{p} \quad$ Drill pipe radius

$R_{w b} \quad$ Wellbore radius

$\begin{array}{ll}\mathrm{t} & \text { Time } \\ \mathrm{T} & \text { Torque vector } \\ \mathrm{u} & \text { Velocity }\end{array}$

Greek letters

$\alpha \quad$ Volume fraction

$\Gamma_{F} \quad$ Momentum source

$\epsilon \quad$ Eccentricity

$\mu \quad$ Viscosity

$\rho \quad$ Density

$\tau \quad$ Shear stress

$\bar{\tau} \quad$ Viscous stress tensor

$\tau_{y} \quad$ Yield stress

$\dot{\gamma} \quad$ Shear rate

$\omega_{p} \quad$ Particle rotational velocity

Mastaneh Hajipour, m.hajipour@srbiau.ac.ir|'Department of Petroleum Engineering, Faculty of Petroleum and Chemical Engineering, Science and Research Branch, Islamic Azad University, Tehran, Iran. 


\section{Abbreviations}

CC Cuttings concentration

ROP Rate of penetration

RPM Rotations per minute

\section{Introduction}

One of the major problems in directional and horizontal drilling is the transport of drill cuttings to the surface. Cuttings bed development occurs at greater well inclinations provided that the drilling fluid flow rate is not sufficient for hole cleaning. In vertical drilling, the cuttings fall in the opposite direction of the drilling fluid flow, but in directional drilling the fluid flow has a reduced vertical component to transport the cuttings to the surface. This decreases the fluid capability to carry the cuttings and leads to solid particles settlement [1]. Efficient wellbore cleaning can prevent problems such as accumulation of drill cuttings inside the well annulus, stuck pipe, lost circulation, high torque and drag, and it can reduce the cost of the drilling operation [2].

Researchers have shown that cuttings transport is affected by many parameters which can be categorized into three groups including fluid properties, cuttings characteristics and operational parameters. An increase in the rate of penetration can minimize the drilling cost but at the same time it would increase the cuttings concentration in the annulus. The overloading of the cuttings in the annulus due to high penetration rate will cause drilling problems, which sometime require unnecessary fishing operation. Therefore, to maintain an acceptable and effective hole cleaning, compromising of the drilling conditions is necessary [3].

Many efforts have been made to study the problem of cuttings transport and the effective factors. Some of the conducted studies are focused on experimental investigations, and some are based on theoretical studies [4-10]. However, high costs of experimental equipments have motivated the researchers to use numerical methods and computerized simulation. Computational Fluid Dynamic (CFD) is one of the efficient tools which is usually employed for this purpose. CFD modeling provides an alternative way to investigate fluid flow in complex geometries and high velocities. Moreover, CFD methods help to analyze complex flow problems that is impossible to investigate experimentally. Specifically, solid-liquid two-phase flow problems under a wide range of flow conditions and sediment characteristics can be evaluated $[6,11-16]$.

Several approaches are available for predicting solid-liquid behavior, particularly for drilling applications. The Eulerian continuum approach, Lagrangian trajectory approach and the kinetic theory modelling for interparticle collisions have been proved useful $[17,18]$. However, the most common method of analysis of cuttings transport phenomena is the Reynolds-averaged Navier-Stokes equations implemented within the Eulerian framework [19-22].

Yilmaz investigated the effects of well inclination, drilling fluid properties, and drill pipe rotational velocity on cuttings transport using Lagrangian-Eulerian coupling scheme and predicted experimental data with good accuracy. It was shown that the value of drilling fluid yield point is an important parameter for efficient hole cleaning [23]. Rooki et al. developed a two-phase Eulerian model to investigate the effect of foam properties as drilling fluid and well deviation on cuttings transport by numerical simulation. Their findings indicated that foam with higher viscosity had better transport ratio [24]. Dyke et al. developed a computational fluid dynamics model to investigate the drill cuttings transport in annular space. The effect of different parameters including rotation of drill pipe, velocity of drilling fluid, well deviation and rate of penetration on accumulation of drill cuttings in drilling wells with different sizes were investigated. The analysis of the effects of parameters individually and in combination were reported [25].

In this study, cuttings transport was simulated in a concentric and eccentric annular section, in a horizontal wellbore. CFD simulations were performed to solve the governing equations for steady-state two phase flow in turbulent condition. In this regard, the drilling fluid was treated as a continuum and the cutting particles were treated as a discrete phase. The Navier Stokes equations and Newton's laws of motion were solved numerically while interaction forces between the two phases were taken into account. Simulation results were compared with the experimental data available in the literature.

The effects of operational parameters i.e., drilling rate, drillpipe rotation and eccentricity, cuttings characteristics i.e., solid particles size and density, and drilling fluid properties i.e., mud density, rheology, and velocity on the performance of cuttings transportation were investigated and the cuttings concentration were calculated to predict the hole cleaning efficiency. The results of this study can be used in predicting the effect of different parameters on hole cleaning efficiency in horizontal drilling.

\section{CFD modeling}

\subsection{Mathematical method}

The Lagrangian-Eulerian/discrete element method (LE/ DEM) approach was adopted for simulation of two phase liquid-solid flow in the annulus of a horizontal well. 
The fluid phase was assumed to be incompressible and non-Newtonian. The solid particles were considered as spherical particles and their movements were governed by Newton's second law. The fluid phase is treated as a continuum, described by Navier-Stokes equations and the particles are treated as a discrete phase. The simultaneous solution of the Navier-Stokes equations and Newton's laws of motion takes into account the interaction forces between the two phases. DEM method allows interparticle and particle-wall collisions to be accurately captured.

In order to account for the turbulent flow the standard k- $\omega$ model was considered the most suitable due to its better performance for wall bounded flows involving rotation. Herschel-Bulkley model was used for prediction of non-Newtonian behavior of the drilling fluid. The governing equations of two phase flow are as follows:

- Equation of continuity for phase $i$ :

$\frac{\partial}{\partial t}\left(\alpha_{i} \rho_{i}\right)+\nabla \cdot\left(\alpha_{i} \rho_{i} u_{i}\right)=0$

where $\alpha$ denotes phase volume fraction, $u$ is velocity and $\rho$ refers to density. The drilling fluid and cutting particles were assumed to be incompressible, so Eq. (1) is simplified due to constant densities.

$\frac{\partial \alpha_{i}}{\partial t}+\nabla \cdot\left(\alpha_{i} u_{i}\right)=0$

- Equation of momentum conservation for drilling fluid $\frac{\partial}{\partial t}\left(\alpha_{f} \rho_{f} u_{f}\right)+\nabla \cdot\left(\alpha_{f} \rho_{f} u_{f} u_{f}\right)=-\alpha_{f} \nabla P+\alpha_{f} \nabla \cdot \bar{\tau}+\alpha_{f} \rho_{f} g-\Gamma_{F}$

where $\mathrm{P}$ is fluid pressure, $\bar{\tau}$ is viscous stress tensor and $\Gamma_{F}$ is momentum source term and calculated as the ratio of the total fluid interaction forces on all particles present in a particular computational cell, to the fluid volume within that cell.

- Equation of motion for cutting particles

$\frac{\partial u_{p}}{\partial t}=g\left(1-\frac{\rho_{f}}{\rho_{p}}\right)+F$

$F$ is the sum of forces per unit mass exerted on particles, defined as:

$F=F_{S}+F_{M}+F_{D}+F_{P}+F_{c}$

where $F_{S}$ is shear lift force, $F_{M}$ is rotational lift (i.e., Magnus force), $F_{D}$ is drag force, $F_{P}$ is pressure gradient force, and $F c$ is contact force which are simulated according to the available models in the literature [26-29]. $\frac{d}{d t}\left(I_{p} \omega_{p}\right)=T$

where $I_{p}$ is particle moment of inertia, $\omega_{p}$ is rotational velocity, and $T$ is the sum of torque vectors acting on particles. The fluid and solid phases are shown by $f$ and $s$ subscripts, respectively. The above coupled and nonlinear partial differential equations were solved by numerical methods using CFD simulator.

Drilling fluid and the cuttings flow through an annulus which could be thousands of feet but simulating a multiphase flow in such an enormous medium is computationally time consuming, and just a section of a horizontal well is used in numerical computations [22]. Therefore, the temperature variation is not considerable.

\subsection{Drilling fluid and cuttings phase}

The rheological behavior of drilling fluid plays an important role in efficient cuttings transport in drilling operations. Drilling fluids exhibit non-Newtonian behavior and the fluid viscosity is affected by temperature, pressure and shear rate. Various rheological models are used to represent the non-Newtonian behavior of drilling fluid among which the Herschel-Bulkley model is the most appropriate model [30, 31]. Herschel-Bulkley model is a classical three parameter rheological model, which is expressed as follows [32]:

$\left\{\begin{array}{lll}\tau & =\tau_{y}+K \dot{\gamma}^{n} & \tau>\tau_{y} \\ \dot{\gamma}=0 & \tau<\tau_{y}\end{array}\right.$

where $\tau$ and $\tau_{y}$ are shear stress and yield stress, respectively, $K$ is consistency factor, $n$ is power law index, and $\dot{\gamma}$ denotes shear rate.

To compare the performance of non-Newtonian drilling fluid with a Newtonian fluid, simulations were carried out using water as drilling fluid based on experimental data of Tomren et al. [4]. The drilling fluid in this study was considered as Herschel-Bulkley fluid with properties shown in Table 1 at $90^{\circ} \mathrm{F}$. Cutting particles were assumed spherical with a mean diameter of 0.25 in [4].

Table 1 Rheological properties of drilling fluids

\begin{tabular}{llll}
\hline Fluid & $n$ & $K$ & $\begin{array}{c}\text { Yield point } \\
\left(\mathrm{lb}_{\mathrm{f}} / 100 \mathrm{ft}^{2}\right)\end{array}$ \\
\hline Water & 1 & 1 & 0 \\
LVM $^{\mathrm{a}}$ & 0.68 & 0.00084 & 2 \\
$\mathrm{HVM}^{\mathrm{b}}$ & 0.61 & 0.0093 & 17 \\
\hline
\end{tabular}

${ }^{\mathrm{a}}$ Low viscosity mud

${ }^{\text {bHigh viscosity mud }}$ 


\subsection{Model geometry and boundary conditions}

Flow geometry was considered as an annulus comprised of two horizontal cyliders. The inner and outer cylinders represent the drill pipe and borehole, respectively. In drilling operation, drilling fluid is injected to drill pipe and convey drill cuttings to the surface through annulus. The length of the annulus can be thousands of feet and a fully developed flow is formed. Therefore, for saving computational time, a section of the annulus with fully developed length was modeled. In this regard, a horizontal annulus with inner diameter of 1.9 in and outer diameter of 5 in was modeled. Several simulations were carried out to calculate the hydrodynamic entrance length. Results revealed that the hydrodynamic entrance length is less than $40 \mathrm{ft}$ and the flow was developed, thus, the simulated well length was considered $40 \mathrm{ft}$ in this study.

In horizontal drilling, the drill string does not remain in the center of the wellbore and moves down by gravity. Drill string eccentricity is defined by the following equation:

$\epsilon=\frac{D}{R_{w b}-R_{p}}$

where $R_{p}$ denotes the radius of drill pipe, $R_{w b}$ is the radius of wellbore, and $D$ is the distance between the centers of the drill pipe and the wellbore.

The outer wall that represents the wellbore considered as a stationary wall and the inner wall was modelled with clockwise a rotation from 0 to $200 \mathrm{rpm}$. However, in some cases, both walls considered stationary in order to simulate cases with no drillpipe rotation. The wall boundaries were treated as no-slip condition. The inlet and outlet boundary conditions were considered as Mass Flow Inlet and Ambient Pressure Outlet, respectively. Figure 1 shows model geometry and the applied boundary conditions.

The cuttings mass flow rate at the annulus inlet was calculated based on the bit penetration rate as follows:

$\dot{m}_{p}=R O P \times A_{w b} \times \rho_{p}$

It should be noted that the effect of formation porosity on the value of $R O P$ should be taken into account. The volume fraction of drill cuttings at the annulus inlet was

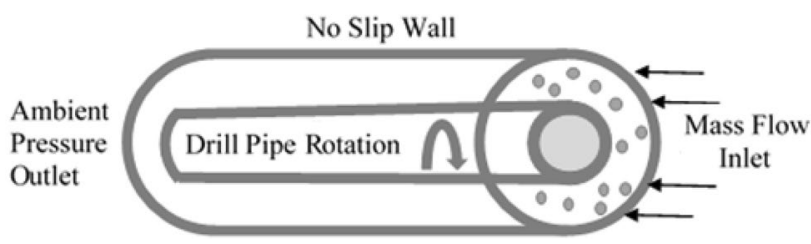

Fig. 1 Geometry domain and boundary conditions calculated by dividing the volumetric flow rate of cuttings over the drilling fluid flow rate. The cuttings mass flow rate at the annulus inlet was considered $0.33 \mathrm{lbm} / \mathrm{s}$ which is representative for ROP of $70 \mathrm{ft} / \mathrm{h}$ whilst the formation porosity considered as 10\%. CFD simulations were carried out using the commercial software ANSYS Fluent 18. The particles collisions were simulated using the softsphere approach, in which the two particles deform after they collide. The deformation is expressed by an overlap displacement of the particles [29]. The collision of particles were taken into account with the Hertzian-Dashpot model. The simulations were run with Young's modulus and Poisson ratio of $4.5 \times 10^{10} \mathrm{~Pa}$ and 0.24 , which corresponds with the experimental data of Tomren et al. [4]. The restitution and the friction coefficients were considered to be 0.9 and 0.09 , respectively [7]. Table 2 shows the geometrical and operational parameters used for simulation.

When using Coupled DEM, particles mass flow rate is a required input parameter which could be converted into the number of particles injected per unit time. Different methods for creating parcels are available in ANSYS Fluent. Details of these methods are presented in the ANSYS Fluent User's Guide. In the present study, because the used particles were relatively large $(d p=0.25$ in), the Standard method was selected. According to this method, considering the particles mass flow rate of $0.33(\mathrm{lbm} / \mathrm{s})$, approximately 432 parcels per second were injected into the annulus. The number of parcels in the domain is varied with time and operating parameters (i.e., fluid properties, RPM, drill pipe eccentricity, and etc.).

\subsection{Mesh independence and computational algorithm}

The drilling fluid and particles behavior were predicted by solution of the governing partial differential equations in three-dimensional cylindrical coordinate system.

Table 2 Simulation input parameters

\begin{tabular}{ll}
\hline Parameter & Value \\
\hline Drill pipe diameter (in) & 1.9 \\
Wellbore diameter (in) & 5 \\
Simulated well length (ft) & 40 \\
Hole inclination ( ${ }^{\circ}$ ) & 90 \\
Drilling fluid flow rate (GPM) & $60-235$ \\
Drill pipe rotation (RPM) & $0,50,100,200$ \\
Cuttings diameter (in) & 0.25 \\
Cuttings density (pcf) & 163.5 \\
Drilling fluid density (pcf) & 63 \\
Drill pipe eccentricity & $0,0.5,0.6,0.75$ \\
Drilling fluid & Water, LVM, HVM \\
\hline
\end{tabular}




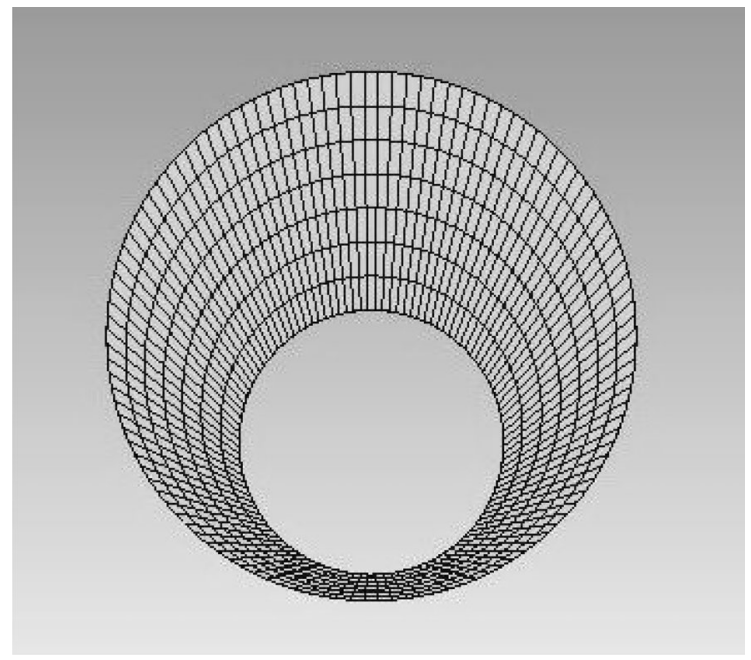

Fig. 2 Computational grid on the cross section of the eccentric annulus

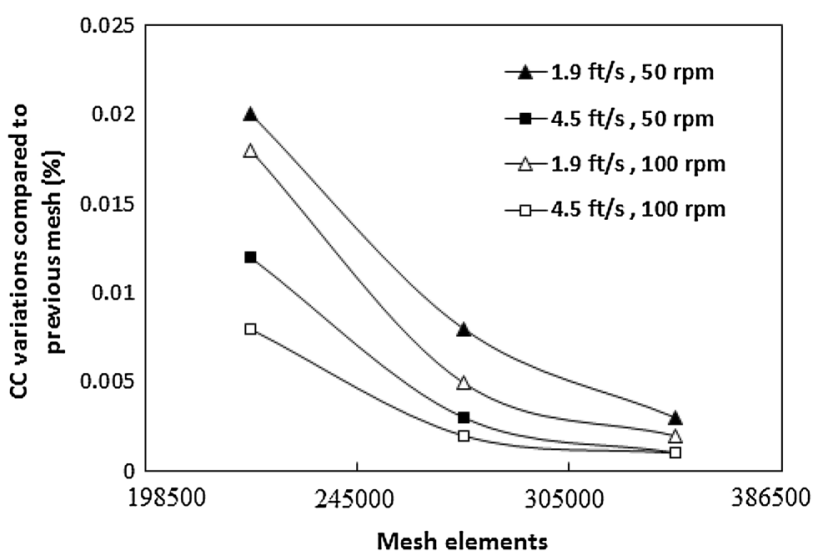

Fig.3 Mesh independence study

The governing equations were numerically solved in a discretised domain using finite-volume formulation. The computational mesh was implemented using structured hexahedral grids for the concentric and eccentric geometries. The computational grid on the cross section of the annulus is displayed in Fig. 2. A grid independence study was carried out and the obtained results showed that with a mesh of 305,000 computational cells, the grid independent solution could be obtained. Figure 3 shows the mesh independence analysis for different fluid velocities and drillpipe rotations. It is evident that by increasing the mesh elements more than 305,000 , the improvement in the results are negligible (i.e., lower than $0.005 \%$ ).

The SIMPLE algorithm developed by Patankar and Spalding was applied to solve the coupled governing equations [33]. To increase the accuracy of numerical calculation of momentum and turbulent diffusion parameters, the second order upwind scheme was employed. The spatial discretisation of volume fraction was applied using QUICK method. Iterative calculations were progressed until the normalised residuals for all equations reached the convergence criterion (i.e., $10^{-6}$ ).

\section{Model validation}

The reliability of simulation results needs to be verified with the data of experimental studies. In the literature, experimental data of velocity profiles of solid particles flowing in non-Newtonian fluids are scarce. In order to validate CFD predictions, numerical results of the cuttings concentration were compared with experimental studies of Tomren et al. [4].

According to Sifferman et al., the cuttings transport efficiency can be expressed as the ratio of the average cuttings transport velocity to the average fluid annular velocity [34]. A higher cuttings transport ratio means there is a relatively lower cuttings concentration in the wellbore. In our study, cuttings transport efficiency was evaluated in terms of cuttings concentration or particles volume fraction in the annulus that is the ratio of the volume occupied by solid particles to the total annulus volume in steady state flow. The lower the cuttings concentration in the annulus, the better the transport performance.

Figures 4 and 5 show comparison of CFD simulation results with experimental data of Tomren et al. [4]. Figure 4 indicates accurate computational results of cuttings concentration for different fluid inlet velocities with and without drill pipe rotation. The drilling fluid is Newtonian and the flow regime is turbulent. The maximum discrepancy between numerical results and experimental data was found at lower fluid velocities. Figure 5 demonstrates the validity of numerical results for Newtonian fluid i.e., water and non-Newtonian fluid i.e., low viscosity mud (LVM) as drilling fluid. The rotational speed of the drill pipe is constant at $50 \mathrm{rpm}$. Simulation results are in good agreement with experimental data with maximum relative error less than $8.2 \%$.

\section{Results and discussion}

Simulation results are presented and discussed for fully developed liquid-solid two phase flow in a horizontal annulus. The low viscosity mud with properties shown in Table 1 was considered as a Hershel-Bulkley non-Newtonian drilling fluid. The impact of various drilling parameters including drill pipe rotation and eccentricity, particle diameter and density, drilling fluid viscosity, density, and flow rate was investigated on hole cleaning efficiency. The 

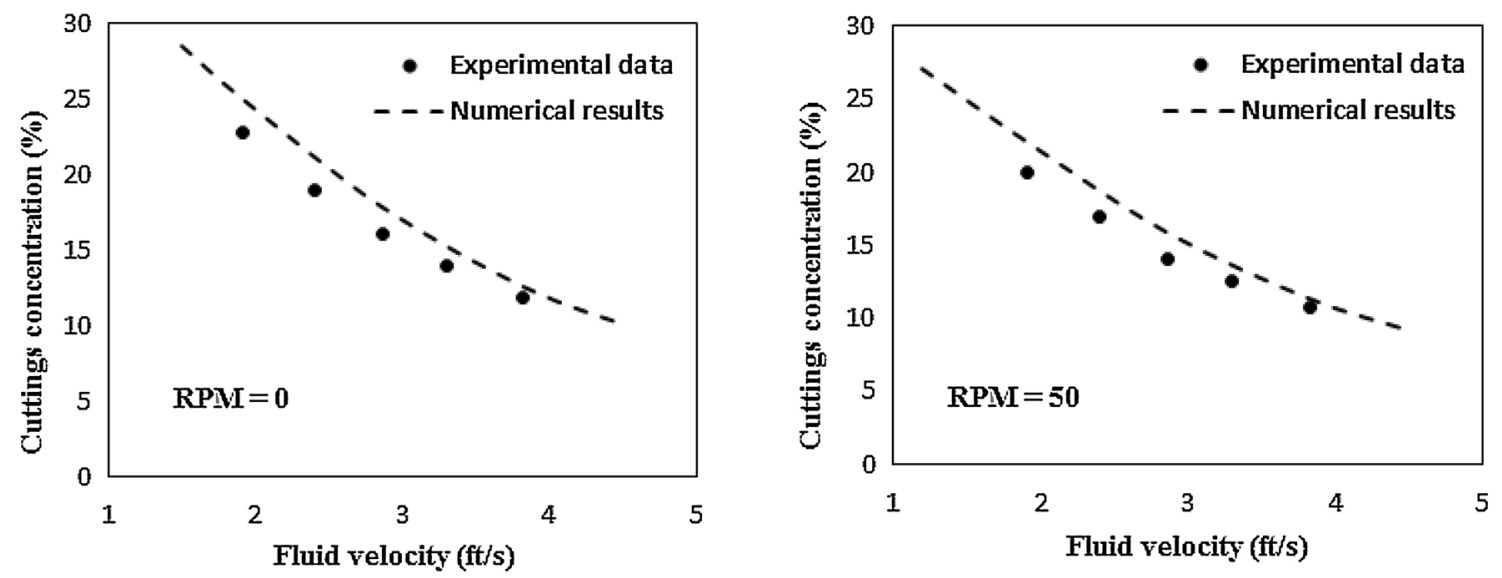

Fig. 4 Comparison of CFD results with experimental data of Tomren et al. [4]

Fig. 5 Comparison of CFD results with experimental data [4], a water and b LVM
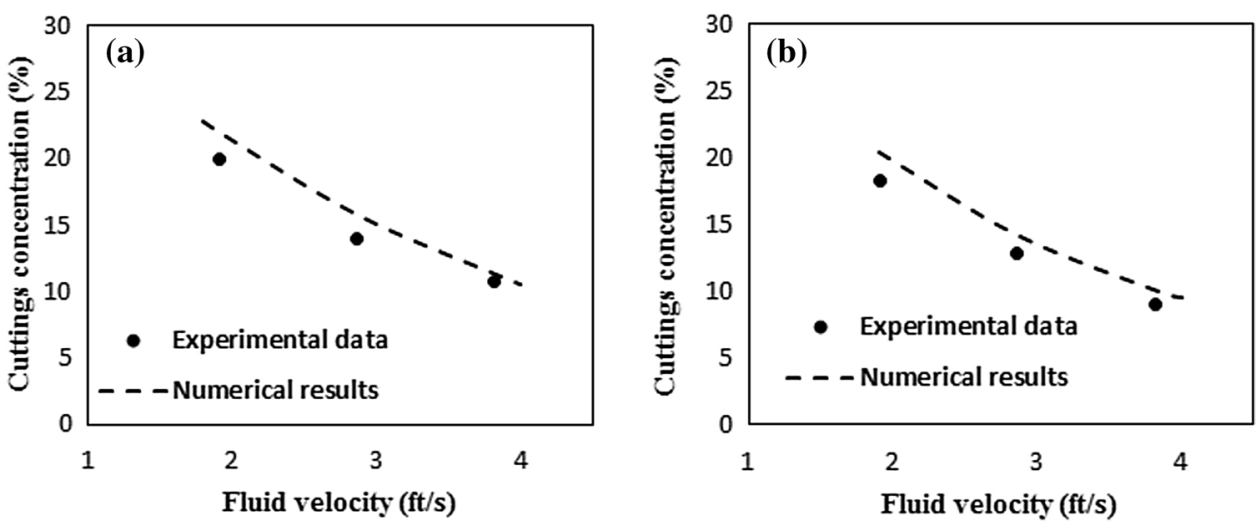

Table 3 Reynolds number for different drilling fluid

\begin{tabular}{llll}
\hline Drilling fluid & HVM & LVM & Water \\
\hline $\operatorname{Re}$ & $10,173,118$ & $86,881,733$ & 26,878 \\
\hline
\end{tabular}

values of various parameters were selected from field data and according to the literature. Transient simulation was run until statistically stationary state was achieved i.e., a constant value for cuttings concentration was reached and the results were illustrated and discussed at steady state conditions. To ensure the turbulent flow, the values of Reynolds number were calculated for non-Newtonian fluids [35]. The values of Reynolds number at minimum fluid velocity are displayed in Table 3 and confirm the flow turbulence.

\subsection{Effect of drill pipe rotation and eccentricity}

In Fig. 6a, the effect of drill pipe rotation on cuttings concentration for various fluid velocities is demonstrated. As it can be seen, an increase in drill pipe rotation tends to reduce the cuttings concentration in the annulus. In fact, increasing the drill pipe rotational speed reduces the slip velocity and phase segregation and therefore, improves the efficiency of the cuttings transport process. Moreover, the drill pipe rotation motivates the cuttings to travel in the center region of the annulus due to the lifting effect. It is obvious from Fig. 6a that higher fluid flow rate causes the cuttings concentration to decrease and lower the impact of drill pipe rotation on cuttings transport performance. Therefore, increasing the drill pipe rotation above an optimum value is not necessary because negligible improvement is achieved in cuttings transport efficiency.

With a slow rotation of drill pipe, an intensive drop in the cuttings accumulation was observed, which indicates that the drill pipe rotation is a significant parameter in horizontal drilling, especially in lower fluid velocities. Table 4 illustrates the cuttings concentration (CC) and the hole cleaning efficiency improvement (EI) for different values of drill pipe rotation relative to the case without rotation. It can be seen that for all fluid velocities, the increase of drill pipe rotation enhances the cuttings transport efficiency. However, the drill pipe rotation is more effective 
Fig. 6 Effect of a drillpipe rotation and $\mathbf{b}$ eccentricity on cuttings concentration
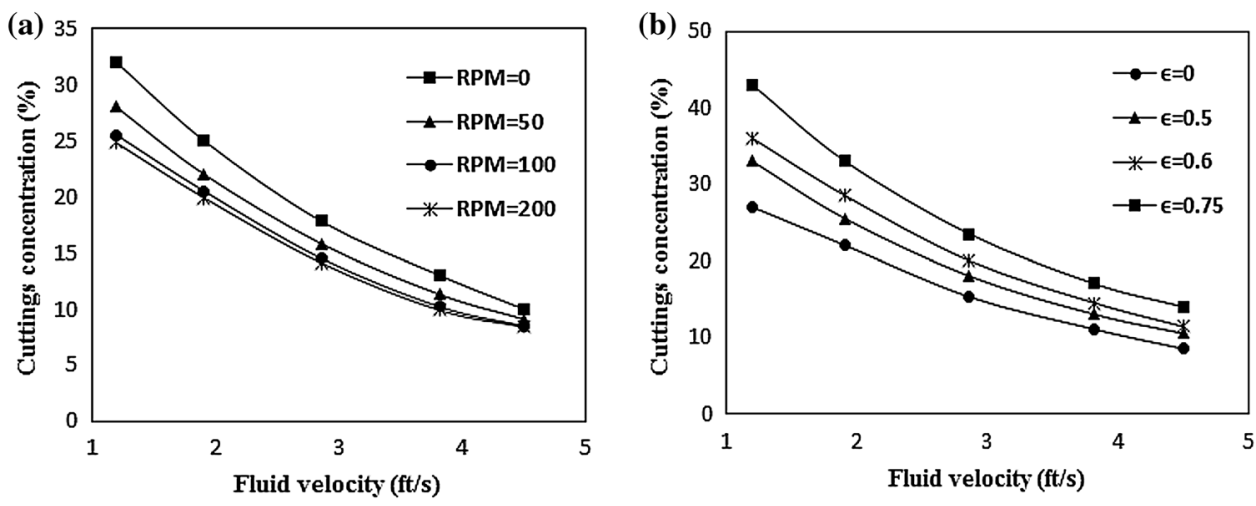

Table 4 Hole cleaning efficiency improvement for various RPM values

\begin{tabular}{lrll}
\hline $\begin{array}{l}\text { Fluid } \\
\text { velocity } \\
\text { (ft/s) }\end{array}$ & RPM & CC (\%) & El (\%) \\
\hline 1.9 & 0 & 25.02 & - \\
& 50 & 22.01 & 12.0 \\
& 100 & 20.51 & 18.0 \\
& 200 & 19.90 & 20.5 \\
4.5 & 0 & 10.03 & - \\
& 50 & 9.11 & 9.2 \\
& 100 & 8.49 & 15.3 \\
& 200 & 8.45 & 15.7 \\
\hline
\end{tabular}

and helpful in lower fluid velocities. According to simulation results in Table 4, increasing the drill pipe rotational velocity more than $100 \mathrm{rpm}$ is not essential and has little effect on hole cleaning efficiency improvement.

In horizontal drilling, the drill pipe has a tendency to rest on the cuttings bed. Therefore, the impact of various drill pipe eccentricities on cuttings accumulation in the annulus was investigated and shown in Fig. 6b. The drill pipe rotation was kept constant at $50 \mathrm{rpm}$. As can be seen in this figure, at constant fluid velocity, by increasing the drill pipe eccentricity the cuttings concentration increases in the annulus. The impact of drill pipe eccentricity on cuttings transport performance is aggravated at lower fluid velocities. For fluid velocity of $1.2 \mathrm{ft} / \mathrm{s}$, the cuttings concentration increased from 27 to $43 \%$, while the pipe eccentricity increased from 0 to 0.75 .

The cuttings transport becomes more severe by increasing the drill pipe eccentricity, therefore higher fluid flow rates are needed for the same hole cleaning behavior. Furthermore, in highly eccentric cases, the cuttings concentration is increased and the height of the particles bed raises for lower fluid velocities.

The combined effect of eccentricity and RPM on cuttings concentration for cases of concentric and $50 \%$ eccentric drill pipe without and with rotation of 100

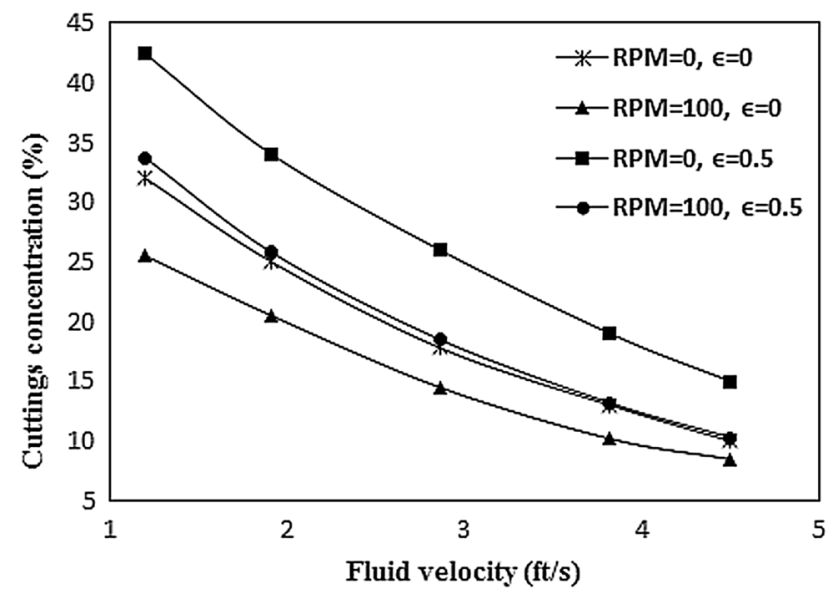

Fig. 7 Combined effect of drill pipe rotation and eccentricity on cuttings concentration

rpm is compared and shown in Fig. 7. It is evident, the drill pipe rotational speed has an intensive effect on cuttings concentration reduction in the annulus. Moreover, increasing the drilling fluid flow rate and consequently its velocity has always positive impact on cuttings concentration decline.

Figure 7 shows that the effect of drill pipe rotation on cuttings concentration is more in eccentric cases. The cuttings concentration for eccentric drill pipe (i.e., $\epsilon=0.5$ ) with $100 \mathrm{rpm}$ rotation is similar with concentric case (i.e., $\epsilon=0$ ) without rotation due to higher drill pipe rotational speed. This could be the result of drill pipe contact with the settled cuttings which causes dispersion of solid particles into the center of the annulus and leads to more cuttings transfer. It can be concluded that in horizontal drilling with high drill pipe eccentricity the drill pipe rotation is an essential parameter. Considering that the drill pipe deviation from the center is inevitable in horizontal drilling, selecting a proper value for drill pipe rotational velocity is needed for an efficient hole cleaning. 


\subsection{Effect of drilling fluid rheology and density}

The effect of drilling fluid rheology on cuttings concentration is shown in Fig. 8a. In this figure, the performance of a Newtonian drilling fluid i.e., water is compared with two non-Newtonian fluids including low viscosity mud (LVM) and high viscosity mud (HVM). The properties of non-Newtonian fluids are reported in Table 1. It can be seen that the suspension ability of water is not enough to keep the efficient transport of cutting particles in the annulus due to lower viscosity compared to drilling muds. It is shown that cuttings concentration decreases by increasing the drilling fluid viscosity. The point to be mentioned here is that the increment of drilling fluid viscosity increases the fluid resistance against the drill pipe rotation and therefore raises the shear stress applied on the drill string. By increasing the fluid velocity, the difference between the cuttings concentration in non-Newtonian drilling fluids is greatly reduced.

The value of drilling fluid viscosity is a function of solid particles concentration. In fact, increasing the solid phase volume fraction due to mud additives or drill cuttings leads to the increase of drilling fluid viscosity.

Figure $8 \mathrm{~b}$ demonstrates the variations of cuttings concentration versus the drilling fluid density for two nonNewtonian fluids. It is shown that increasing the drilling fluid density reduces the cuttings concentration in the annulus. In fact, as the value of the drilling fluid density approaches the value of cuttings density, the two phase mixture behaviour is more like a single phase fluid, thus the particles transport becomes more convenient and the cuttings accumulation is reduced. It should be noted that although the increase of drilling fluid density has positive impact on hole cleaning improvement, but a difficulty might emerge in drilling operation due to higher pumping power requirement.

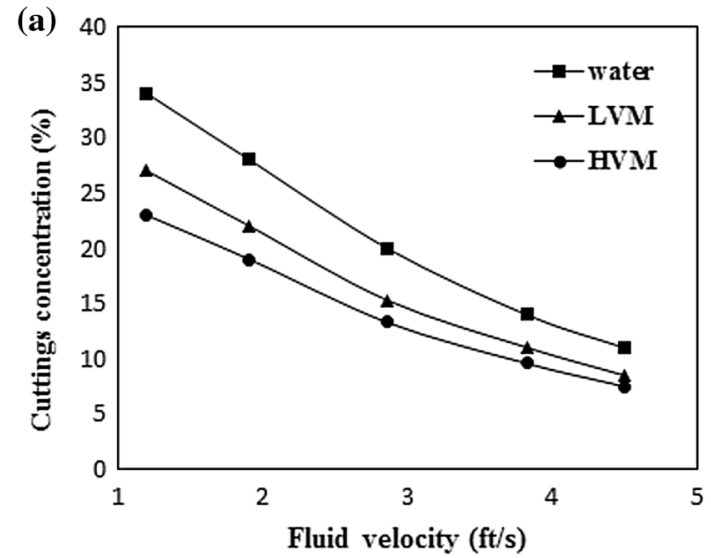

As shown in Fig. 8b, for both non-Newtonian fluids (i.e., LVM and HVM), the cuttings concentration decreases by increasing the fluid velocity. The slope of the lines indicates that the cuttings transport efficiency is more sensitive to the value of fluid density at lower velocities. For both drilling fluids, as the fluid density increases from 63 to $110 \mathrm{pcf}$, the relative increase in cuttings transport efficiency was obtained about $42 \%$ and $51 \%$ for fluid inlet velocity of $1.91 \mathrm{ft} / \mathrm{s}$ and $3.82 \mathrm{ft} / \mathrm{s}$, respectively.

\subsection{Effect of cuttings size and density}

Figure 9a shows the comparison of cuttings concentration for various sizes of particles. As observed in this figure, at a constant fluid velocity, concentration of large particles is lower than fine particles in the annular space. In horizontal drilling, the transport of large particles is mainly affected by fluid flow rate and drag force being exerted on particles. The improvement of the hole cleaning at higher particle diameters is due to the larger drag force applied to the cuttings by viscous forces.

In a horizontal annulus, the critical velocity for particles rolling decreases with particle size which leads to easier transport and enhanced hole cleaning for larger particles. The transport mechanism of fine particles is mainly dominated by strong particle-particle and particle-fluid interactions therefore, drill pipe rotation and fluid viscosity could have more impacts on hole cleaning.

As can be seen in Fig. 9a, at higher drilling fluid flow rates, the effect of particle size on hole cleaning is more obvious. The concentration difference between the small and large particles increases at higher velocities due to higher drag force applied on the particles. For all particle sizes, as the drilling fluid flow rate increases, particles are transferred easily in the annulus and therefore, the cuttings concentration decreases. As

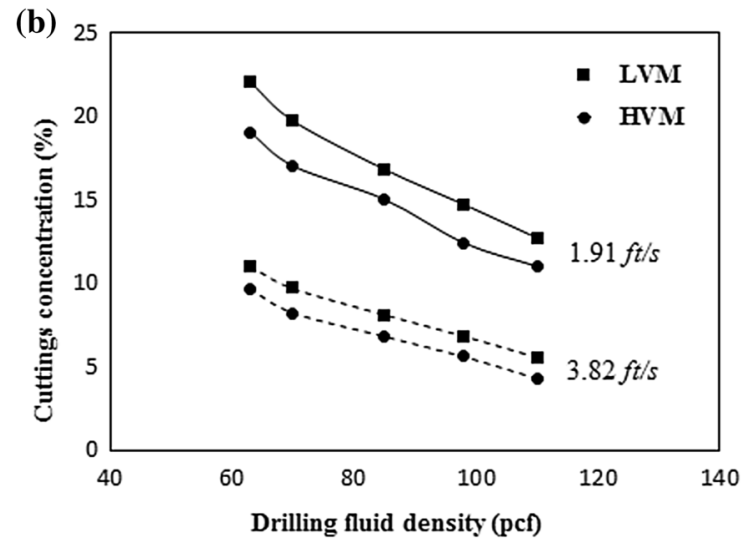

Fig. 8 Effect of $\mathbf{a}$ fluid viscosity and $\mathbf{b}$ fluid density on cuttings concentration 

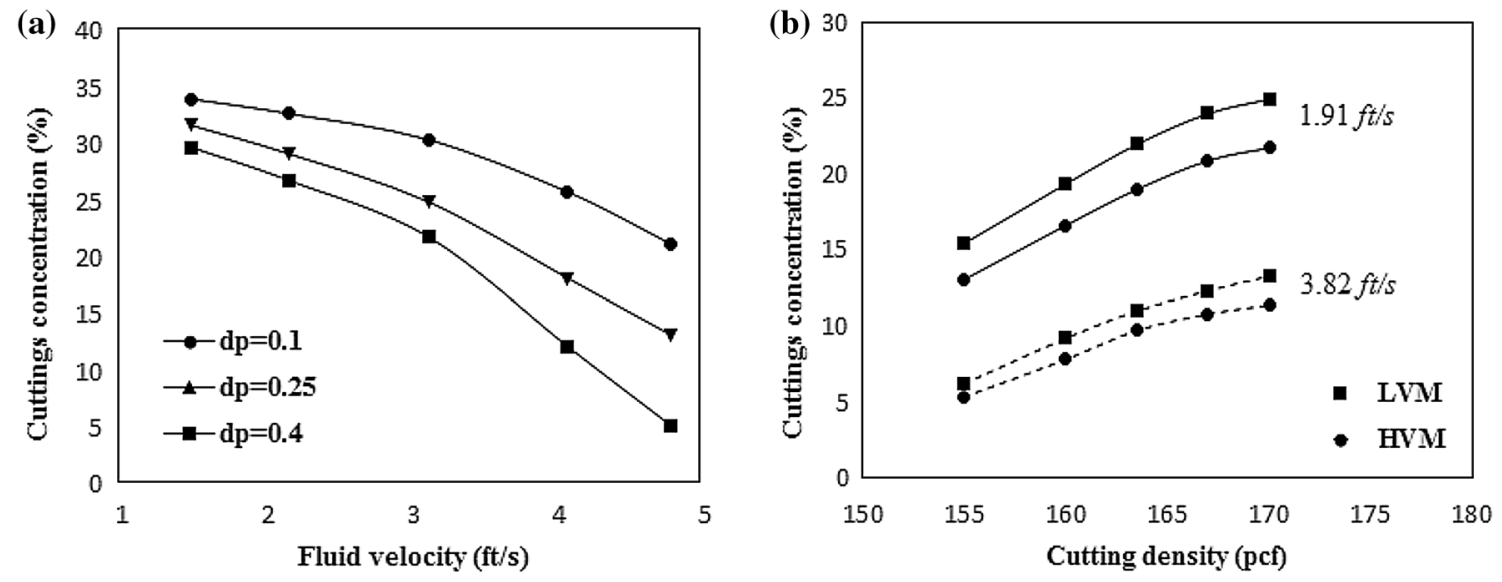

Fig. 9 Effect of a particles size and $\mathbf{b}$ cuttings density on cuttings concentration

the particles diameter increased from 0.1 to $0.4 \mathrm{in}$, the obtained increase in cuttings transport efficiency was $14.7 \%$ and $78.2 \%$ for fluid velocity of $1.5 \mathrm{ft} / \mathrm{s}$ and $4.8 \mathrm{ft} / \mathrm{s}$, respectively.

The effect of drill cuttings density on cuttings concentration in the annulus is shown Fig. 9b. It is clear that the cuttings concentration increases by increasing the solid particles density. The increase of cuttings density raises the density difference between the dispersed and the continuous phases and increases the gravity force applied on the cuttings and consequently increases the settled cuttings in the annulus. This effect is more severe at lower fluid velocities. Moreover, by increasing the solid particles density the difference between the cuttings concentration in low viscosity mud and high viscosity drilling fluid is increased. It can be concluded that the impact of drilling fluid rheology on the cuttings transport efficiency is more noticeable at higher cuttings density. Therefore, the effect of geology variations and formation rock type should be taken into account to design an efficient cuttings transport process.

(a)

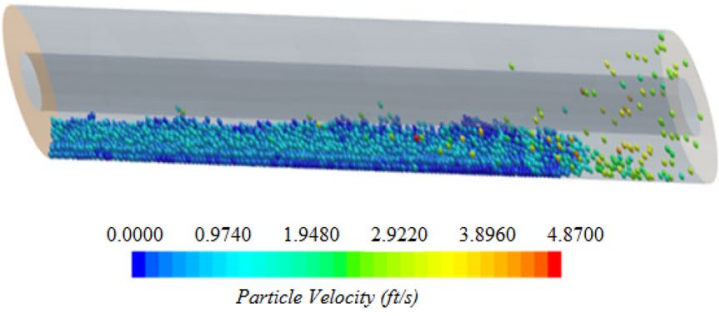

\subsection{Effect of fluid velocity and drilling rate}

Simulation results of particles velocity magnitude and cuttings deposition through the same length of the well hole are shown in Fig. 10 at fluid flow rates of 65 and 235 GPM. The effect of drilling fluid flow rate on cuttings concentration and hole cleaning efficiency is evident. An increment in fluid flow rate increases particles velocity and thus decreases cuttings concentration in the annulus. In fact, as fluid flow rate increases higher drag force is exerted on the solid particles and therefore their deposition concentration decreases. An instantaneous increase in cuttings concentration occurs at lower fluid flow rate. Similar to experimental study of Tomren et al. [4], at steady-state conditions the cutting concentration becomes constant throughout the entire length of the annulus.

Figures $6,7,8,9$ and 10 show simulation results of cuttings concentration for various drilling parameters and different values of fluid inlet velocities. It is clear from these figures that for all variations of drilling parameters the hole cleaning efficiency improves at higher fluid velocities.

The impact of the Rate of Penetration (ROP) on cuttings transport is illustrated in Fig. 11. As can be seen, increasing

(b)

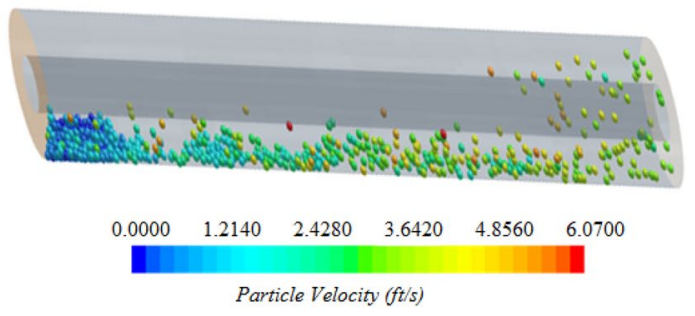

Fig. 10 Cuttings transport at fluid flow rate of a 65 GPM, b 235 GPM for particles size of 0.25 in, particles density of 163 pcf and 50 rpm drill pipe rotation 
(a)

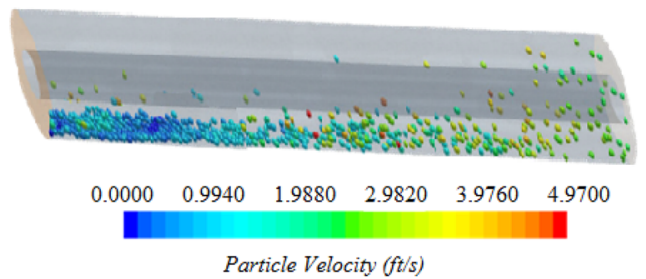

(c)

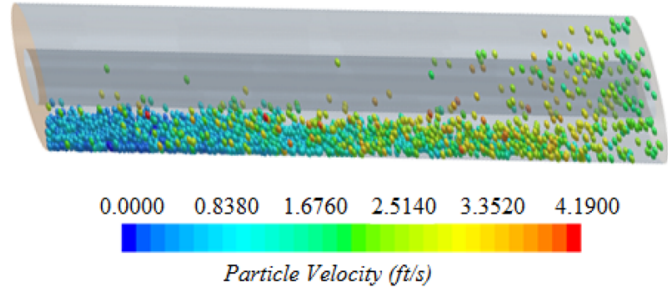

(b)

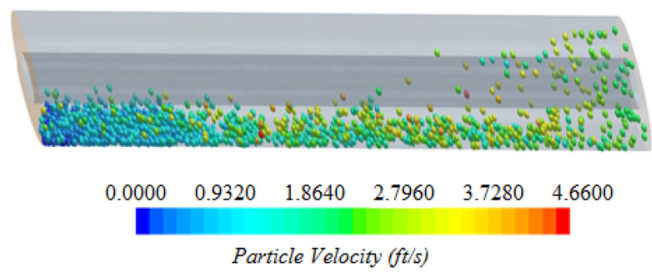

(d)

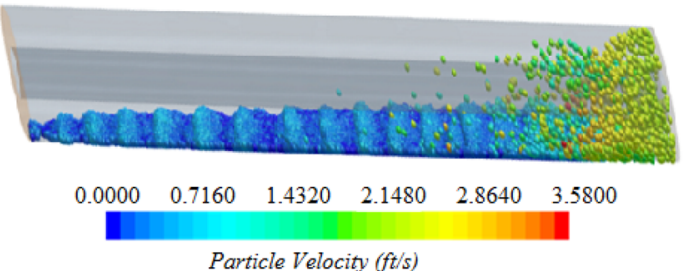

Fig. 11 Cuttings transport at different ROPs a $20 \mathrm{ft} / \mathrm{h}, \mathbf{b} 50 \mathrm{ft} / \mathrm{h}, \mathbf{c} 70 \mathrm{ft} / \mathrm{h}, \mathbf{d} 100 \mathrm{ft} / \mathrm{h}$ for particles size of $0.25 \mathrm{in}$, particles density of $163 \mathrm{pcf}$ and 50 rpm drill pipe rotation

the value of ROP leads to more cuttings entering the well annulus which causes an increase in the shear rate and inter-particle frictional forces. Therefore, the kinetic energy of cutting particles decreases and leads to higher cuttings concentration in the annulus. An increment in drilling rate increases particles velocity fluctuations and disrupts free particle movements, thus increases the particles accumulation in the borehole.

For higher values of ROP, while other parameters are constant, the drill cuttings concentration in the cross section of the annulus raises and the hole cleaning becomes more severe, thus, higher fluid flow rates are necessary for the same hole cleaning efficiency. Most of the time, decreasing the drilling rate is not economic and therefore drilling fluid flow rate should be adjusted properly in order to have an efficient hole cleaning. In fact, maintaining a proper value for ROP and drilling fluid flow rate is a simple solution for hole cleaning problem regardless of changing the drilling fluid properties.

(a)

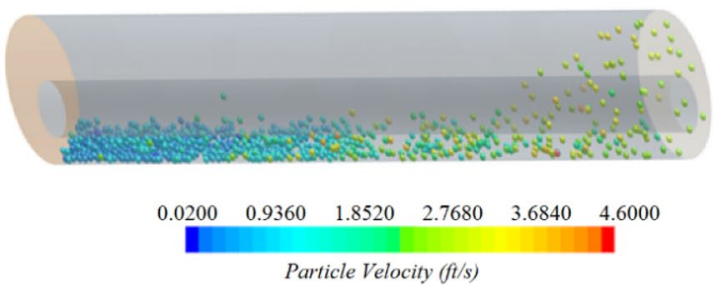

Fig. 12 Particles velocity at different drill pipe eccentricities a 0.5, b 0.3
The increase of ROP results in abrupt reduction of cuttings transport efficiency especially in higher eccentricities. For eccentric drill pipe, in addition to fluid flow rate the rotational speed of drillpipe should be increased to overcome the particles deposition.

Figure 12 depicts the velocity of cuttings in the annulus with different eccentricities. This figure illustrates the impact of drill pipe eccentricity on cuttings accumulation in the annulus while other parameters were kept constant. It is evident that in cases with higher eccentricities, the flow area available for the cuttings at the bottom of the annulus decreases which causes the particles velocity reduction and cuttings settlement. The decrease of solid particles velocity leads to increase the cuttings concentration and bed formation in the annulus. In fact, the more the drillpipe lean downward, the more the cuttings will accumulate.

(b)

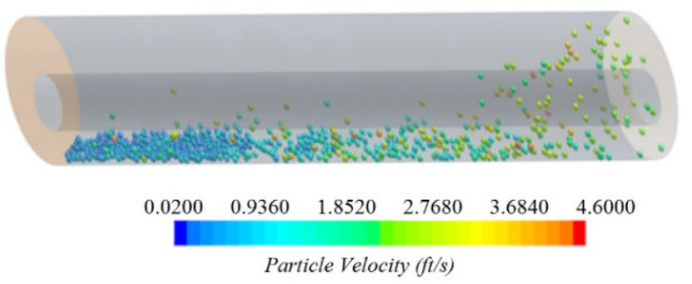




\section{Conclusions}

In this study, a coupled LE-DEM model was applied to simulate cuttings transport under turbulent conditions in horizontal drilling. The effects of various parameters on the cuttings transport including drill pipe rotation and eccentricity, cuttings size and density, drilling fluid rheology, density and velocity were investigated and discussed. Simulation results were compared with the experimental data and good agreement was obtained which shows the capability and reliability of CFD analysis to simulate the drilling operation. Numerical results indicate that at constant drilling rate, the major factors that affects the hole cleaning in horizontal wellbores are drill pipe rotational speed, drilling fluid velocity and rheology. The main findings are as follows.

- Drill pipe rotation increases the shear force exerted on solid particles and leads to the dispersion of settled cuttings in the annulus especially for higher eccentricities. As drill pipe rotational speed increased from 0 to $100 \mathrm{rpm}$, the cuttings concentration in the annulus decreased from 42.4 to $33.7 \%$ for a constant velocity of $1.2 \mathrm{ft} / \mathrm{s}$ and eccentricity of 0.5 .

- By increasing the drill pipe eccentricity, particles velocity in the bottom side of the annulus decreases due to reduced cross sectional area. Therefore, solid particles eventually settle in the medium they are flowing through, which results in decreasing particle transport at constant fluid flow rate. For fluid velocity of $1.2 \mathrm{ft} / \mathrm{s}$, the cuttings concentration increased from 27 to $43 \%$, while the pipe eccentricity increased from 0 to 0.75 for a rotational speed of $50 \mathrm{rpm}$.

- The sensitivity analysis carried out on cuttings parameters reveals that particles with smaller diameter and lower density are more dispersed in the annulus and therefore, transported easily compared to large diameter particles. Moreover, coarse particles impose eddies of various sizes onto the mean flow and enhance the flow turbulence intensity, which leads to decelerate the cuttings transport.

- Increasing the drilling fluid density can improve the hole cleaning efficiency, however the increase in pumping power requirement should be taken into account.

- Cuttings accumulation in the annulus decreases by increasing the fluid viscosity, as the suspension ability of drilling fluid for efficient transport of particles increases.

- The increase of drilling fluid flow rate and reduction of ROP.

- have positive impacts on efficient cuttings transport and maintaining a proper value for the ratio of these two parameters are essential for effective hole cleaning. The relative increase in cuttings transport efficiency was about $66.3 \%$ as fluid velocity increased from 1.2 to $4.5 \mathrm{ft} / \mathrm{s}$ in concentric annulus with $50 \mathrm{rpm}$ rotational speed.

Results of this study indicate the potential of CFD analysis for predicting cuttings transport performance in turbulent flow conditions. Moreover, saving in time and cost is obtained using CFD simulation method in comparison with difficult experimental measurements especially at high fluid velocities. Therefore, using a reliable CFD model leads to decrease the difficult experimental measurements.

\section{Compliance with ethical standards}

Conflict of interest The author states that there is no conflict of interest.

\section{References}

1. Sifferman TR, Becker TE (1992) Hole cleaning in full-scale inclined wellbores. SPE Drill Eng 7(2):115-120

2. Ozbayoglu EM, Miska SZ, Reed T, Takach N (2003) Cutting transport with foam in horizontal and highly-inclined wellbores. In: SPE/IADC drilling conference, Amsterdam, 19-21 February

3. Zhu X, Yi J, Liu Q (2015) Distribution features of cuttings bed and sensitivity analysis of major drilling parameters for cuttings transport in gas drilling horizontal wells. J Hydrodyn 27(6):884-893

4. Tomren PH, lyoho AW, Azar JJ (1986) Experimental study of cutting transport in directional wells. SPE Drill Eng 1(1):43-56

5. Zhu X, Sun C, Tong H (2013) Distribution features, transport mechanism and destruction of cuttings bed in horizontal well. J Hydrodyn 25(4):628-638

6. Wang R, Cheng R, Wang H, Bu Y (2009) Numerical simulation of transient cuttings transport with foam fluid in horizontal wellbore. J Hydrodyn 21(4):437-444

7. Akhshik S, Behzad M, Rajabi M (2015) CFD-DEM approach to investigate the effect of drill pipe rotation on cuttings transport behavior. J Pet Sci Eng 127:229-244

8. Wazed A (2002) A parametric study of cutting transport in vertical and horizontal well using computational fluid dynamics (CFD). Dissertation, West Virginia University, Morgantown

9. Zhu X, Sun C, Tong H (2013) Distribution features, transport mechanism and destruction of cuttings bed in horizontal well. J Hydrodyn Ser B 25(4):628-638

10. Gumati A, Takahshi H (2011) Experimental study and modeling of pressure loss for foam-cuttings mixture flow in horizontal pipe. J Hydrodyn 23(4):431-438

11. Gao Y, Chen Y, Cai D, Liu H, Liu C, Li Q (2018) Axial laminar velocity field calculation and optimization for power-law fluid in eccentric annulus with cutting bed. J Hydrodyn 30(5):943-949

12. Pereira FAR, Ataide $\mathrm{CH}$, Barrozo MAS (2010) CFD approach using a discrete phase model for annular flow analysis. Lat Am Appl Res 40:53-60 
13. Han SM, Hwang YK, Woo NS, Kim YJ (2010) Solid-liquid hydrodynamics in a slim hole drilling annulus. J Pet Sci Eng 70:308-319

14. Al-Kayiem HH, Mohd Zaki N, Asyraf MZ, Elfee ME (2010) Simulation of the cuttings cleaning during the drilling operation. Am J Appl Sci 7(6):800-806

15. Zhonghou S, Haizhu W, Gensheng L (2011) Numerical simulation of the cutting-carrying ability of supercritical carbon dioxide drilling at horizontal section. Pet Explor Dev 38(2):233-236

16. Hajidavalloo E, Sadeghi Behbahani Zadeh M, Shekari Y (2013) Simulation of gas-solid two-phase flow in the annulus of drilling well. Chem Eng Res Des 91(3):477-484

17. Fan LS, Zhu C (2005) Principles of gas-solid flows. Cambridge University Press, Cambridge

18. Epelle El, Gerogiorgis DI (2018) Transient and steady state analysis of drill cuttings transport phenomena under turbulent conditions. Chem Eng Res Des 131:520-544

19. Sorgun M (2010) Modeling of Newtonian fluids and cuttings transport analysis in high inclination wellbores with pipe rotation. Dissertation, Middle East Technical University, Ankara

20. Rooki R, Ardejani F, Moradzadeh A (2015) CFD simulation of rheological model effect on cuttings transport. J Dispers Sci Technol 36(3):402-410

21. Rooki R, Doulati Ardejani F, Moradzadeh A, Norouzi M (2014) Simulation of cuttings transport with foam in deviated wellbores using computational fluid dynamics. J Pet Explor Prod Technol 4(3):263-273

22. Heydari O, Sahraei E, Skalle P (2017) Investigating the impact of drillpipe's rotation and eccentricity on cuttings transport phenomenon in various horizontal annuluses using computational fluid dynamics (CFD). J Pet Sci Eng 156:801-813

23. Yilmaz D (2012) Discrete phase simulations of drilled cuttings transport process in highly deviated wells. Dissertation, Istanbul Technical University, Istanbul

24. Rooki R, Doulati Ardejani F, Moradzadeh A, Norouzi M (2014) Simulation of cuttings transport with foam in deviated wellbores using computational fluid dynamics. J Pet Explor Prod Technol 4:1-11

25. Dykes GB (2014) Cutting transport implications for drill string design: A study with computational fluid dynamics. Dissertation, College of Earth Resource Sciences and Engineering, Golden
26. Laín S, Sommerfeld M (2008) Euler/Lagrange computations of pneumatic conveying in a horizontal channel with different wall roughness. Powder Technol 184:76-88

27. Oesterlé B, Bui Dinh T (1998) Experiments on the lift of a spinning sphere in a range of intermediate Reynolds numbers. Exp Fluids 25(1):16-22

28. Sommerfeld M (2000) Theoretical and experimental modelling of particulate flow: overview and fundamentals. Technical report lecture series no. 2000-6. RhodeSaint Genèse, Belgium, Von Karman Institute for Fluid Mechanics

29. Di Renzo A, Di Maio FP (2004) Comparison of contact-force models for the simulation of collisions in DEM-based granular flow codes. Chem Eng Sci 59(3):525-541

30. Munawar K, Badrul MJ, Abdul Raman AA (2011) Rheological and statistical evaluation of nontraditional lightweight completion fluid and its dependence on temperature. J Pet Sci Eng 77(1):27-33

31. Xu C, Yuan $L, X u Y$, Hang W (2010) Squeeze flow of interstitial Herschel-Bulkley fluid between two rigid spheres. Particuology 8(4):360-364

32. Huilgol RR, You Z (2005) Application of the augmented Lagrangian method to steady pipe flows of Bingham, Casson and Herschel-Bulkley fluids. J Nonnewton Fluid Mech 128(2):126-143

33. Patankar SV, Spalding DB (1972) A calculation procedure for heat, mass and momentum transfer in three-dimensional parabolic flows. Int J Heat Mass Transf 15(10):1787-1806

34. Sifferman TR, Myers GM, Haden EL, Wahl HA (1974) Drillcuttings transport in full-scale vertical annulus. J Pet Technol 26(11):1295-1302

35. Bourgoyne AT, Millheim KK, Chenevert ME, Young FS (1986) Applied drilling engineering. Society of Petroleum Engineers, Richardson

Publisher's Note Springer Nature remains neutral with regard to jurisdictional claims in published maps and institutional affiliations. 